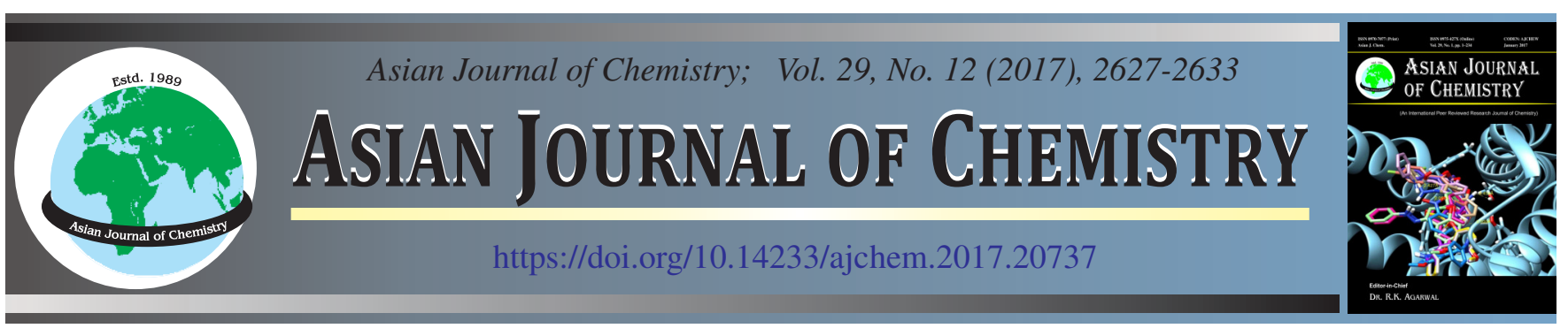

\title{
Sensitive and Validated Voltammetric Methods for Determination of Zileuton in Serum, Urine and Pharmaceutical Dosage Forms at Activated Glassy Carbon Electrode
}

\author{
Nabil A. Alhemiary ${ }^{1,2, *}$ and Moustfa A. RizK ${ }^{1,3}$
}

\author{
${ }^{1}$ Department of Chemistry, College of Science and Arts - Sharurah, Najran University, Sharurah, Saudi Arabia \\ ${ }^{2}$ Department of Chemistry, College Science, Ibb University, Ibb, Yemen \\ ${ }^{3}$ Department of Chemistry, College of Science, Suez Canal University, Ismailia, Egypt \\ *Corresponding author: E-mail: alhemyri1000@yahoo.com
}

\begin{abstract}
A simple, precise and sensitive voltammetric methods determination of zileuton were presented at activated glassy carbon electrode in Britton-Robinson buffer of $\mathrm{pH} 8$ by differential pulse voltammetry and square wave voltammetry methods. A study of the variation of the peak current with solution variables such as $\mathrm{pH}$, ionic strength, concentration of drug, possible interference and instrumental variables such as scan rate, pulse amplitude, accumulation potential, has resulted in the optimization of the reduction signal for analytical purposes. Linear calibration plots were obtained over the concentration ranges of $2.0 \times 10^{-6}$ to $1.2 \times 10^{-5}$ and $1.0 \times 10^{-6}$ to $1.8 \times 10^{-5} \mathrm{~mol} / \mathrm{L}$, respectively, using differential pulse voltammetry and square wave voltammetry methods. The correlation coefficients were 0.9977 and 0.9947 for differential pulse voltammetry and square wave voltammetry methods, respectively. The linear response was obtained in Britton-Robinson buffer in the range of $2.0 \times 10^{-6}-2.0 \times 10^{-5}$ and $2.0 \times 10^{-6}-3.1 \times 10^{-5} \mathrm{~mol} / \mathrm{L}$ for spiked serum and urine samples, respectively. The limit of detection (LOD) and limit of quantification (LOQ) were $1.3 \times 10^{-9}$ and $3.95 \times 10^{-9} \mathrm{~mol} / \mathrm{L}$ for differential pulse voltammetry method and $2.34 \times 10^{-10}$ and $6.99 \times 10^{-10} \mathrm{~mol} / \mathrm{L}$ for square wave voltammetry method. The RSD for five measurements were 0.0489 and 0.0885 using $50 \mathrm{mV} / \mathrm{s}$ scan rate. The methods were applied for the determination of zileuton drug in dilute serum, urine samples and pharmaceutical dosage form with satisfactory results and compared with the official reference method. Complete validation of the proposed method was also done.
\end{abstract}

Keywords: Zileuton, Differential pulse voltammetry, Square wave voltammetry, Cyclic voltammetry, Activated glassy carbon electrode.

ᄂ - - - - - - - - - - - - - - - - - - - - - - - -

\section{INTRODUCTION}

Zileuton [R,S-( \pm )-N-(1-(benzo[b]thien-2-yl) ethyl)-Nhydroxyurea] (Fig. 1) and is an anti-asthma drug that differs chemically and pharmacologically from other anti-asthmatic agents [1,2]. Zileuton is indicated for the prophylaxis and chronic treatment of asthma in adults and children 12 years of age and older [3]. It blocks leukotriene synthesis by inhibiting 5-lipoxygenase, an enzyme of the eicosanoid synthesis pathway [1]. Current data indicates that asthma is a chronic inflammatory disorder of the airways involving the production and activity of several endogenous inflammatory mediators, including leukotrienes. Sulfido-peptide leukotrienes (LTC4, LTD4, LTE4, also known as the slow-releasing substances of anaphylaxis) and LTB4 [4,5]. A chemoattractant for neutrophils and eosinophils are derived from the initial unstable product of arachidonic acid metabolism, leukotriene A4 (LTA4) and can be measured in a number of biological fluids including broncho alveolar lavage fluid (BALF) from asthmatic patients [6]. In humans, pretreatment with zileuton attenuated broncho-

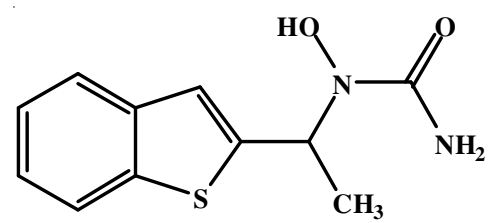

Fig. 1. Structure of zileuton

constriction caused by cold air challenge in patients with asthma [7]. Zileuton is a very slightly soluble compound without any ionizable functional group [8]. Recently, the molecule has been reported in the literature as a new efficient and safe antiacne drug [9]. The methods available for analysis of zileuton in pharmaceutical dosage forms and biological fluids are those utilizing the principles of UV and VIS-spectrophotometry [10,11], HPLC [12-14], HPTLC [15], RP-HPLC [16,17], LC/MSMS [18,19] and polarography [20].

The advantages of electrochemical techniques in drug analysis are their simplicity, low cost and relatively short analysis time compared with other routine analytical techniques. In 
the present study, electrochemical behaviour and oxidationreduction mechanism of zileuton at an activated glassy carbon electrode was investigated using cyclic voltammetry (CV), differential pulse voltammetry (DPV) and square wave voltammetry (SWV). Determination of zileuton in spiked urine, spiked serum samples and in pharmaceutical dosage forms was also investigated using DPV and SWV.

\section{EXPERIMENTAL}

The electrochemical analyzer computerized system with 797 VA computerized software (1.0) from Metrohm, Swizerland was used. A three-electrode system was used, including a glassy carbon electrode as the working electrode. A digital $\mathrm{pH} / \mathrm{mV}$ meter (Jeanway 3510) with a glass combination electrode was used for the preparation of the buffer solution. An Oxford adjustable micropipette (Huawei, Ireland) was used to measure microliter volumes of the drug standard solutions. The sigma 4-5 L centrifuge, Sigma (USA) was used to centrifuge the urine and serum samples, which were then suitable for voltammetric analysis.

The chemicals and reagents used were of analytical reagent grade and some of them were used as such without any further purification. Distilled water was used throughout all experiments. Zileuton (purity $99.8 \%$ ) were supplied by Spimaco Addwaeih, Al-Qassim, Saudi Arabia. Stock solution of $1.0 \times$ $10^{-3} \mathrm{~mol} / \mathrm{L}$ zileuton was freshly prepared by dissolving a calculated weighed of the active ingredient drugs in deionized water and stored at $4{ }^{\circ} \mathrm{C}$ in PVC containers. More diluted solutions were freshly prepared daily by accurate dilution. $0.04 \mathrm{~mol} / \mathrm{L}$ Britton-Robinson buffer between $\mathrm{pH}$ 4-12 were used as the supporting electrolytes. All solutions were prepared from AnalaR grade reagents (Sigma-Aldrich) in doubly distilled water. The calibration curves for DPV and SWV analysis were constructed by plotting the peak current against zileuton concentration.

Optimizations: To obtain the optimum $\mathrm{pH}$, an appropriate amount of zileuton working standard solution $1 \times 10^{-3} \mathrm{~mol} / \mathrm{L}$ was placed in the electrolytic cell, which contained $25 \mathrm{~mL}$ of Britton-Robinson buffer solution and the cyclic voltammogram was recorded. The experiment was repeated by using buffer solutions of different $\mathrm{pH}$ values 4-12 and the optimum $\mathrm{pH}$ was obtained. The effect of different types buffer such as acetate, phosphate and Britton- Robinson buffer on the peak current $\left(\mathrm{I}_{\mathrm{p}}\right)$ of zileuton was studied. The working electrode was immersed in buffer solution of the optimum $\mathrm{pH}$ containing an appropriate amount of the drug stock solution $1 \times 10^{-3} \mathrm{~mol} / \mathrm{L}$, the cyclic voltammogram was recorded. For analytical application, the following parameters being employed: DPV-pulse amplitude $50 \mathrm{mV}$, pulse width $50 \mathrm{~ms}$, scan rate $50 \mathrm{mV} / \mathrm{s}$, SWV-pulse amplitude $25 \mathrm{mV}$, frequency $15 \mathrm{~Hz}$, potential step $4 \mathrm{mV}$, electrochemical analyzer does the background subtraction automatically. For cyclic voltammetry, the initial and final potential values were variable, depending on the $\mathrm{pH}$ value and the cut-off the electrolyte. Scan rate measurements in the range of 10-200 $\mathrm{mV} / \mathrm{s}$ were carried out.

Pre-treatment of glassy carbon electrode: The electrode was pretreated by cycling a square-wave potential with a frequency of $350 \mathrm{~Hz}$ between the potential limits of $\pm 6 \mathrm{~V}$ followed by the application of triangular potential sweep between $\pm 6 \mathrm{~V}$ (frequency $3500 \mathrm{~Hz}$ ) in $0.1 \mathrm{~mol} / \mathrm{L}$ potassium nitrate solution.
Finally, the electrode was subjected to an electrochemical pretreatment by applying a potential of $+1.5 \mathrm{~V}$ for $5 \mathrm{~min}$ and then $-1.0 \mathrm{~V}$ for $2 \mathrm{~s}$ in $0.1 \mathrm{~mol} / \mathrm{L}$ potassium nitrate solution. These steps were repeated until the voltammetric response of the electrode became reproducible. At the end of the procedure, the electrode surface was so stable that for 40 measurements, the electrochemical pretreatment alone was sufficient before each scan [21].

General procedure: Voltammetric analyses were performed in $25 \mathrm{~mL}$ of Britton-Robinson buffer. The solution was continuously stirred at $1200 \mathrm{rpm}$ when accumulation potential (usually open circuit conditions) was applied for a certain time to the working electrode. At the end of accumulation period, the stirring was stopped and after $5.0 \mathrm{~s}$ rest period was allowed for the solution to become quiescent. The used drug was determined by using DPV method. Aliquots of the drug solution of $1 \times 10^{-3} \mathrm{~mol} / \mathrm{L}$ were introduced into the electrolytic cell and the procedure was repeated. The voltammograms were recorded. The peak current was evaluated as the difference between each voltammogram and the background electrolyte voltammogram. All measurements were carried out at room temperature.

Analysis of pharmaceutical dosage form: Tablets containing $600 \mathrm{mg}$ of zileuton per tablet were purchased from local Saudi Arabia market. Ten tablets of zileuton were crushed into a fine powdered in a mortar. A suitable amount of this powder was accurately weighed and then dissolved in $25 \mathrm{~mL}$ methanol. It was sonicated for $5 \mathrm{~min}$. The content was allowed to settle after stirring magnetically for $5 \mathrm{~min}$. The sample solution was filtered through a Whatman no. 42 filter paper. Appropriate solutions were prepared by taking suitable aliquots of the clear supernatant liquid and diluting them with bidistilled water in order to obtain a final solution of $1.0 \times 10^{-3} \mathrm{~mol} / \mathrm{L}$ zileuton. Each solution was transferred to a voltammetric cell and the voltammograms were subsequently recorded following the optimized conditions. The amount of zileuton per tablet was calculated using linear regression equation obtained from the calibration curve of pure zileuton.

Analysis of spiked biological samples: The urine and serum samples, obtained from healthy volunteers was centrifuged (4000 rpm) for $30 \mathrm{~min}$ at room temperature and separated. Serum samples were stored frozen until assay. After gentle thawing, an aliquot volume of samples were fortified with drug sample dissolved in deionized water to achieve final concentration of $1 \times 10^{-3} \mathrm{~mol} / \mathrm{L}$ and treated with $0.4 \mathrm{~mL}$ acetonitrile as serum denaturing and precipitating agent. Acetonitrile is known to remove serum proteins more effectively. The volume was completed to $3 \mathrm{~mL}$ with the same serum sample. The tube was vortexed for $1 \mathrm{~min}$ and then centrifuged for $10 \mathrm{~min}$ at $4000 \mathrm{rpm}$ to get rid of serum protein residues and supernatant was taken carefully. Appropriate volumes of the clean solution were analyzed in the voltammetric cell containing BrittonRobinson buffer, $\mathrm{pH}$ 8.0. Quantification were performed by means of calibration curve methods [22,23].

\section{RESULTS AND DISCUSSION}

Cyclic voltammetry: Anodic cyclic voltammogram for the oxidation-reduction of zileuton in Britton-Robinson buffer at activated glassy carbon electrode is shown in (Fig. 2). It is 
clear that the voltammogram exhibits one anodic and cathodic peaks at $943 \mathrm{mV}$ and $420 \mathrm{mV}$, respectively, which shows a quasi- reversible behaviour, with peak-to-peak separation $\left(\Delta \mathrm{E}_{\mathrm{p}}\right.$ $\left.=\left|E_{p c}-E_{p a}\right|\right)$ of $-523 \mathrm{mV}$. The results suggest the redox couple which shows reversible behaviour with equal number of protons and electrons participated in the working buffer. The zileuton may undergoes protonation with bond cleavage and one electrone loss in the first oxidation step. Then the oxidized product was reduced via gaining electron and deprotonation of the oxidized product. The proposed mechanism of oxidationreduction reaction is shown in Scheme-I.

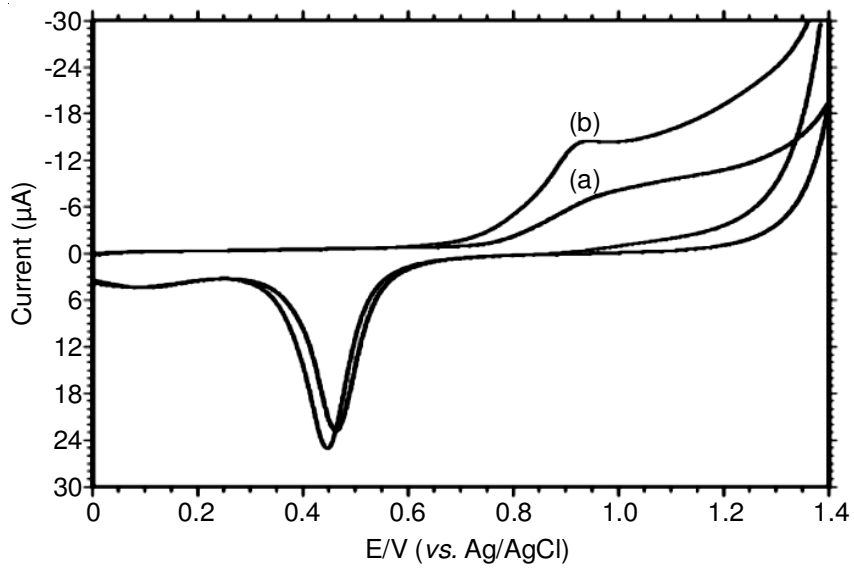

Fig. 2. Cyclic voltammogram of $1 \times 10^{-6} \mathrm{~mol} / \mathrm{L}$ zileuton in Britton-Robinson buffer at $\mathrm{pH} 8.0$; scan rate $=50 \mathrm{mV} / \mathrm{s}$

Effect of pH: The pH of the electrolyte medium is one of the variables that commonly and strongly influenced the shape of the voltammogram and therefore it was important to investigate the effect of the $\mathrm{pH}$ on the electrochemical behaviour of the drug. The effect of $\mathrm{pH}$ on the reduction of the drugs under investigation at activated glassy carbon electrode was studied over the $\mathrm{pH}$ range $4-12$ at same concentration $1.0 \times 10^{-3} \mathrm{~mol} / \mathrm{L}$ of zileuton solution in various electrolytes, such as acetate, phosphate and Briton-Robinson buffers of different ionic strength in the range of 0.04-0.2 $\mathrm{mol} / \mathrm{L}$. It was found that the maximum peak size was obtained at $\mathrm{pH} 8$ in Britton-Robinson buffer, which allows wider range of determination than acetate and phosphate buffers. Hence, it was used as a favourable buffer throughout the study. Fig. 3 shows the effect of $\mathrm{pH}$ on the current peak in a Briton-Robinson buffer of $\mathrm{pH}$ range from 4 to 10 for $2.0 \times 10^{-6} \mathrm{~mol} / \mathrm{L}$ zileuton.

The effect of solution $\mathrm{pH}$ on peak potentials of zileuton at GCE was also investigated. Cyclic voltammograms at different $\mathrm{pH}$ values of 4-12 were shown in Fig. 3., which show that an increase in $\mathrm{pH}$ of the solution caused shift in the oxidative peak potential to the negative direction, indicating that the electrode process is influenced by protonation reactions. A linear correlation between the peak potential and solution $\mathrm{pH}$ was obtained as shown in Fig. 4 with a linear equation and correlation of:

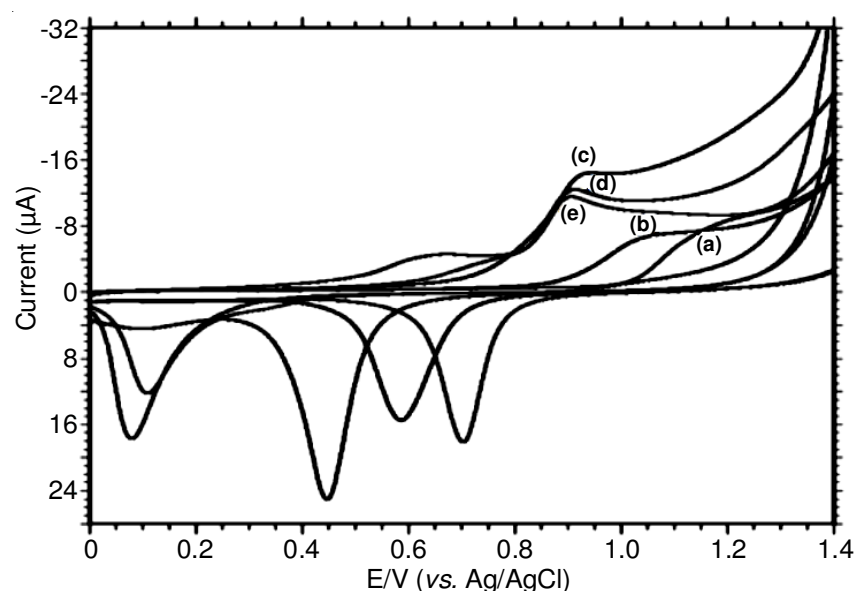

Fig. 3. Cyclic voltammogram obtained for $2.0 \times 10^{-6} \mathrm{~mol} / \mathrm{L}$ zileuton in Britton-Robinson buffer solution at (a) $\mathrm{pH} 4.0$, (b) $\mathrm{pH} 6.0$, (c) $\mathrm{pH}$ 8 , (d) $\mathrm{pH} 10$ and (c) $\mathrm{pH} 12$ with potential; scan rate: $50 \mathrm{mV} / \mathrm{s}$

$$
\mathrm{E}_{\mathrm{pa}}(\mathrm{mV} / \mathrm{s})=1.811-0.114 \mathrm{pH} \mathrm{K} \cdot \mathrm{r}=0.9911
$$

The slope was found to be $0.114 \mathrm{mV} / \mathrm{pH}$, which suggested that the number of proton taking part in the electrode reaction is similar to the number of electrons. Hence, the oxidation of zileuton involves one electron and one proton.

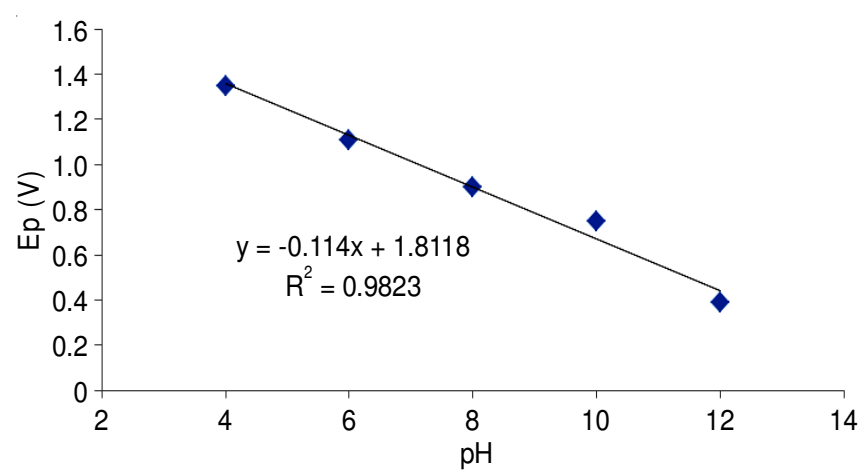

Fig. 4. A linear correlation between the peak potential and $\mathrm{pH}$

Effect of scan rates: The relationship between measured peak current and scan rate was studied over range $10-200 \mathrm{mV} / \mathrm{s}$. It was found to be directly proportional the peak current and the peak potential of zileuton were evaluated as shown in Fig. 5. Scan rate studies were carried out to assess whether the process at the glassy carbon electrode was under diffusion or adsorption controlled process as shown in Fig. 6. The anodic and cathodic peak current of zileuton increases linearly with the square root of scan rate, in the potential range from 10 to $200 \mathrm{mV}$, with eegression $r=0.9954$. A plot of logarithm of peak current versus logarithm of scan rate gave a straight line with a slope very close to the theoretical value of 0.5 , which is expressed for an ideal reaction of diffusion controlled electrode process (Fig. 7) [24]. Also the anodic and cathodic peak potentials of the electrode were shifted toward positive and negative potential,

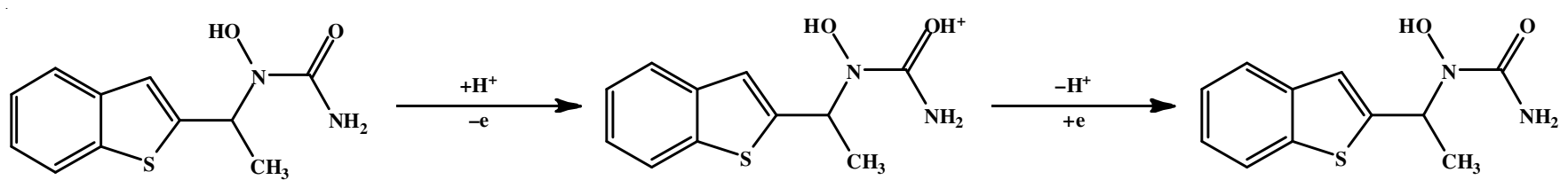

Scheme-I: Proposed mechanism of the oxidation-reduction reaction of zileuton drug 


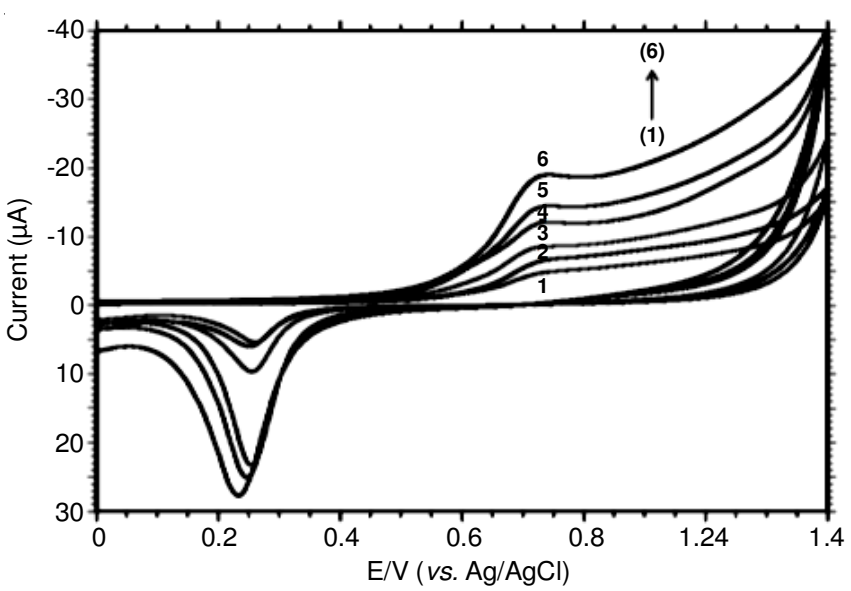

Fig. 5. Cyclic voltammograms of $2.0 \times 10^{-6} \mathrm{~mol} / \mathrm{L}$ zileuton in BrittonRobinson buffer at $\mathrm{pH} 8$ at scan rates of: (1) 10 , (2) 30 , (3) 50, (4) 80, (5) 100, (6) $200 \mathrm{mV} / \mathrm{s}$

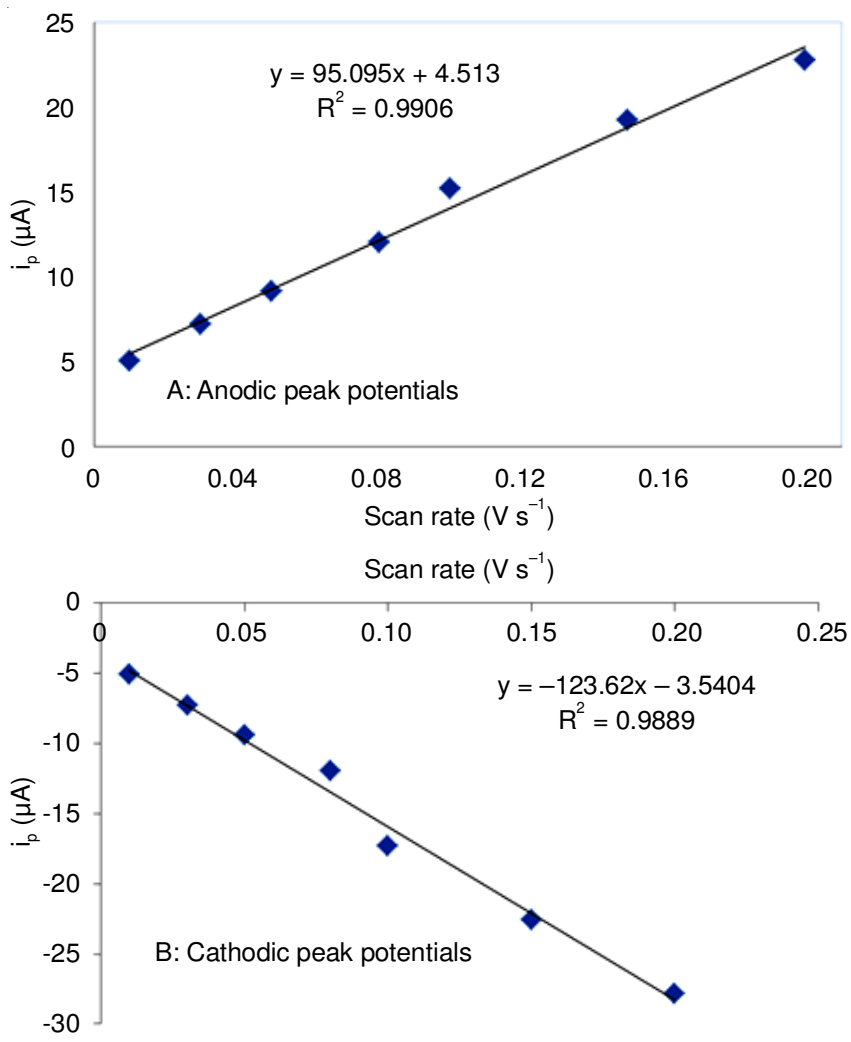

Fig. 6. The anodic (a) and cathodic (b) peak current of zileuton with the square root of scan rate

respectively. This may be attributed to the accumulation of the oxidation or reduction products on the electrode surface.

Effect of accumulation operators: The accumulation of zileuton at GCE surface depends on operational factors, which were additional investigations to ensure sensitive detections of this drug [25]. So, the effect of accumulation time on the efficiency of the collection of $1 \times 10^{-3} \mathrm{~mol} / \mathrm{L}$ zileuton drug on the working electrode surface was evaluated by rising the accumulation time over the range of $0-40 \mathrm{~s}$. The resulting peak current-optimum accumulation time is exhibited in $30 \mathrm{~s}$ (Fig. 8) and as can be seen from this plot, a steady enhancement in the peak current was observed over the range 0-40 s and after that the peak intensity nearly decreased probably due to the satu-
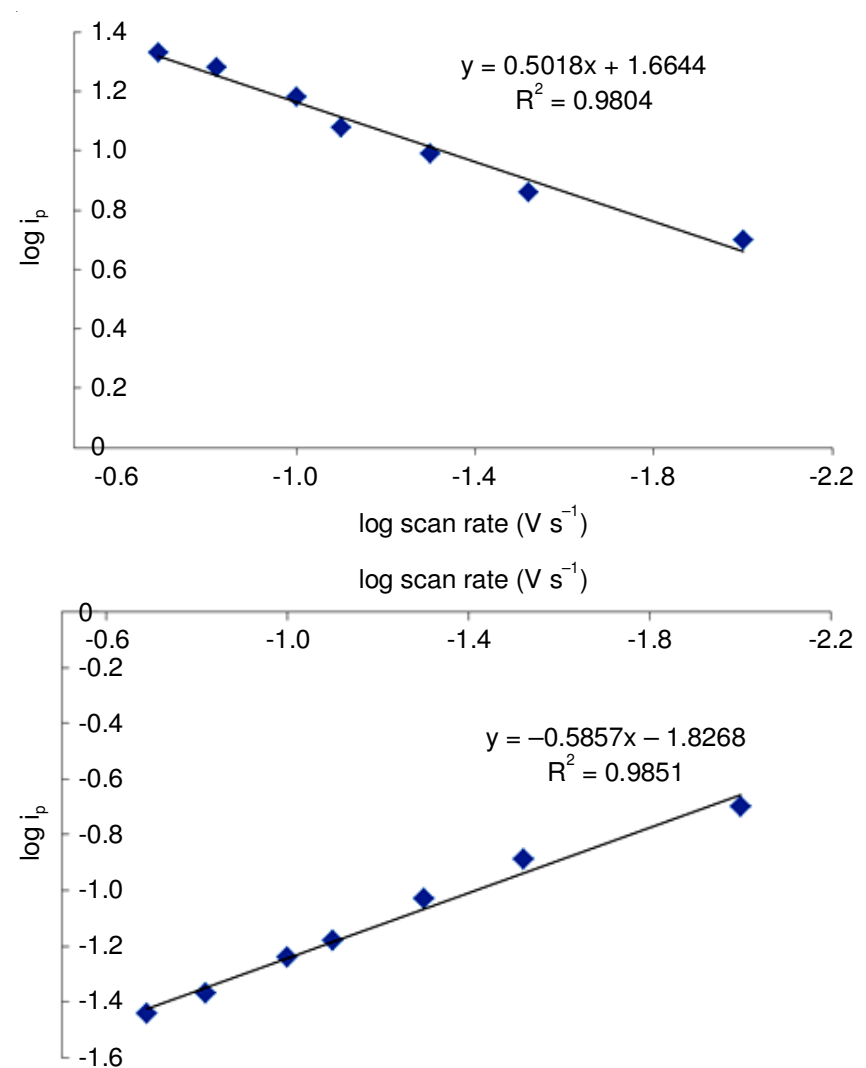

Fig. 7. Relation between $\log i_{p}(\mu \mathrm{A})$ and $\log$ scan rate $(\mathrm{V} / \mathrm{s})$ for oxidation of zileuton drug at activated glassy carbon electrode

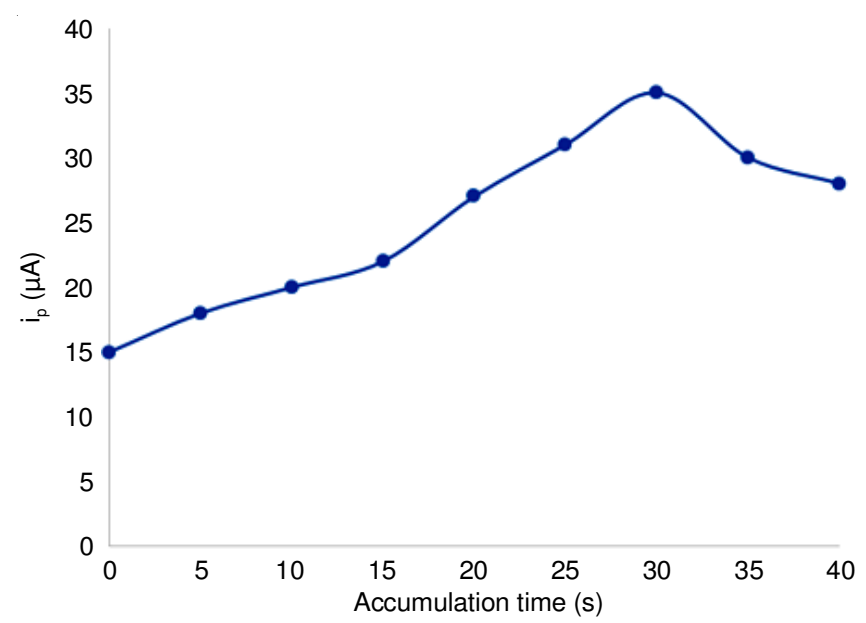

Fig. 8. Effect of accumulation time $\left(\mathrm{t}_{\mathrm{acc}}\right)$ of $2 \times 10^{-6} \mathrm{~mol} / \mathrm{L}$ zileuton peak current at Britton-Robinson buffer, $\mathrm{pH}=8, \mathrm{E}=0.1 \mathrm{~V}$ and scan rate $50 \mathrm{mV} / \mathrm{s}$

ration of the GCE surface. Hence, $30 \mathrm{~s}$ accumulation time was selected for all the future experiments. In a different study, the accumulation potential effect on the peak current of this drug was recorded by variation of accumulation potential from 0.15 $\mathrm{V}$ to $-0.6 \mathrm{~V}$. The maximum anodic peak current value was obtained with an accumulation potential of $0.1 \mathrm{~V}$, which was selected as the optimum value in future experimental studies.

Analytical applications: While the sensitivity enhancement associated with the interfacial accumulation is significant, the main advantage of the method is its inherent selectivity towards the surface-bound analyte. For this purpose the working electrode with the extracted drug was transferred from the complex 
sample to an electrolytic blank solution between the preconcentration and measurement steps.

Differential pulse voltammetry: To develop a quantitative voltammetric evaluation methodology for determining the drug was established on the linear correlation between the peak current and concentration. For analytical purposes we selected the DPV and SWV mode. Differential pulse experiments were performed on the GCE in Britton-Robinson buffer solution at $\mathrm{pH}=8$ with experimental conditions were: scan rate $50 \mathrm{mV} \mathrm{s}^{-1}$; pulse amplitude $50 \mathrm{mV}$; pulse width of $50 \mathrm{~ms}$ and pulse period $40 \mathrm{~ms}$. The potential was scanned anodically from an initial to a final potential of 400-1200 $\mathrm{mV}$ resulting voltammograms shown in Fig. 9, which show that while the peak potential remained almost constant at $0.892 \mathrm{~V}$, the DVP data for the determination of the drug under investigation (Fig. 10) shows a linear relation between the peak current $\left(I_{p}\right)$ and zileuton concentration $(\mathrm{C})$ and was found in the following range: $2 \times 10^{-6}-1.2 \times 10^{-5} \mathrm{~mol} / \mathrm{L}$.

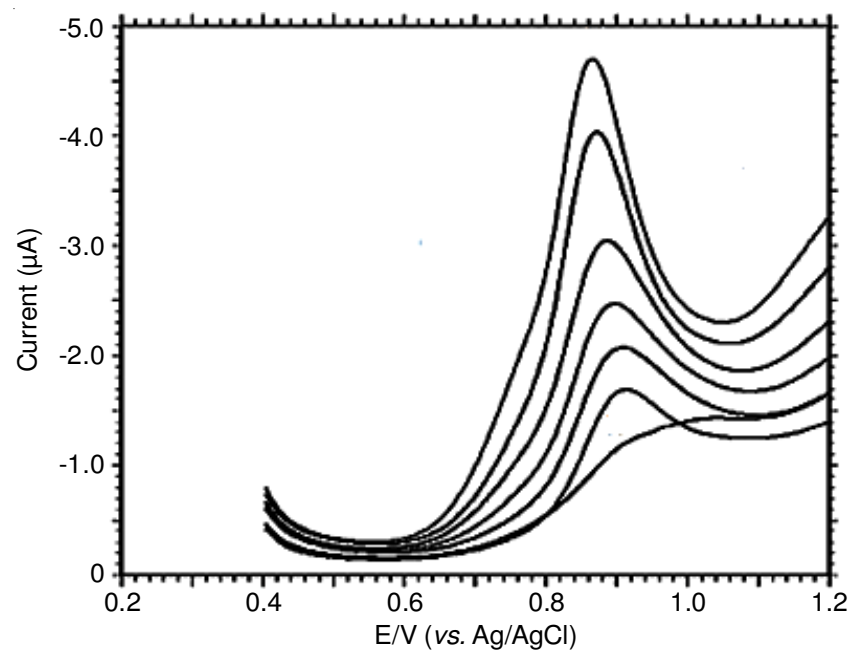

Fig. 9. Differential-pulse voltammograms with increasing concentration of zileuton $\left(2 \times 10^{-6}-1.2 \times 10^{-5} \mathrm{~mol} / \mathrm{L}\right)$ in $\mathrm{pH} 8$ buffer solution on GCE electrode

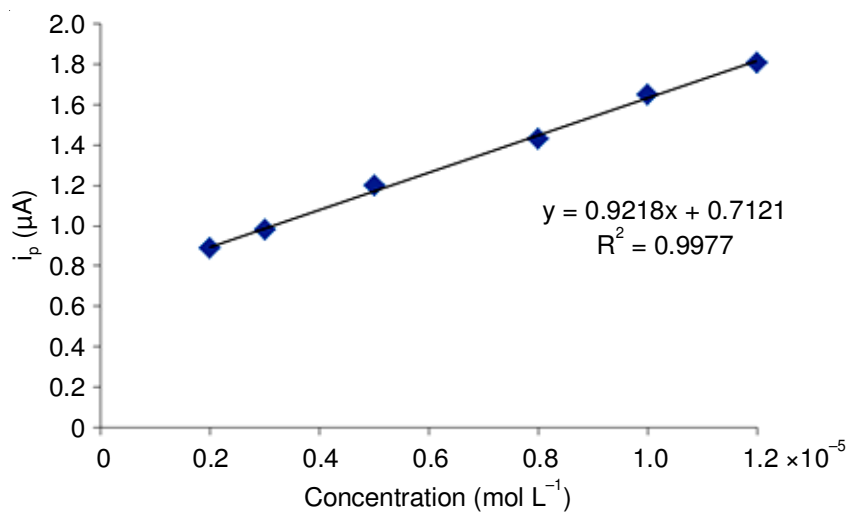

Fig. 10. Calibration graphs of zileuton drug by using DPV method

Square wave voltammetry: The SWV experiments were performed at GCE in Britton-Robinson buffer solution at $\mathrm{pH}$ $=8$ with experimental conditions were: scan rate $50 \mathrm{mV} \mathrm{s}^{-1}$; pulse amplitude $25 \mathrm{mV} ; 4 \mathrm{mV}$ potential step and potential range of 500 to $1000 \mathrm{mV}$ and frequencies $50 \mathrm{~Hz}$. The potential was scanned anodically from an initial to a final potential of 400-
$1200 \mathrm{mV}$ resulting voltammograms are shown in Fig. 11. It shows that while the peak potential remained almost constant at $0.866 \mathrm{~V}$, the SWV data for the determination of the drug under investigation (Fig. 12) shows linear relations between the peak current $\left(\mathrm{I}_{\mathrm{p}}\right)$ and zileuton concentration $(\mathrm{C})$ and was found in the following range: $1 \times 10^{-6}$ to $1.8 \times 10^{-5} \mathrm{~mol} / \mathrm{L}$.

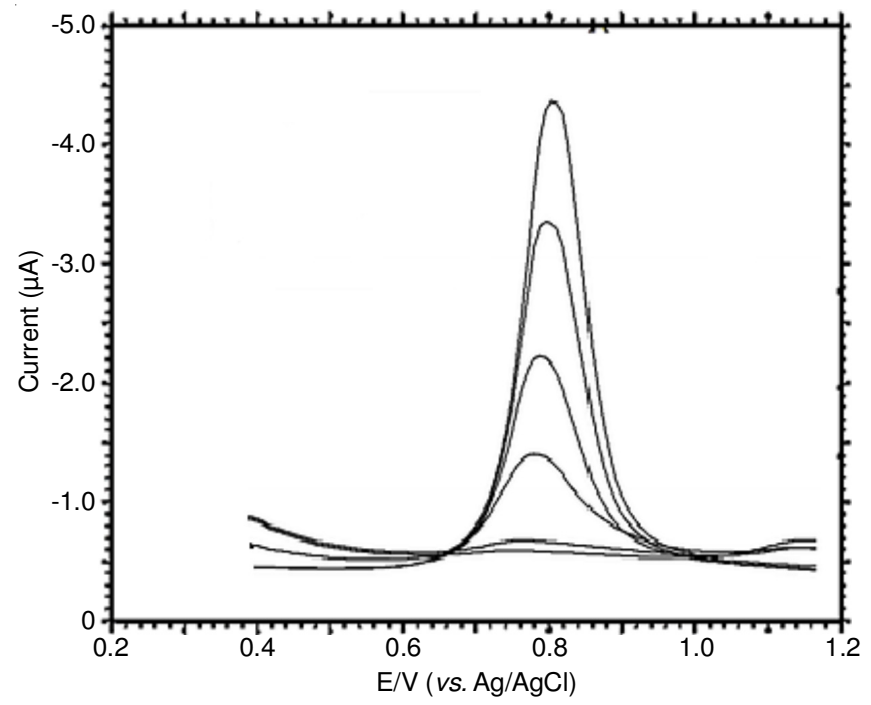

Fig. 11. Square-wave voltammograms with increasing concentration $(1 \times$ $10^{-6}-1.8 \times 10^{-5} \mathrm{~mol} / \mathrm{L}$ ) of zileuton in $\mathrm{pH} 8$ buffer solution on GCE electrode

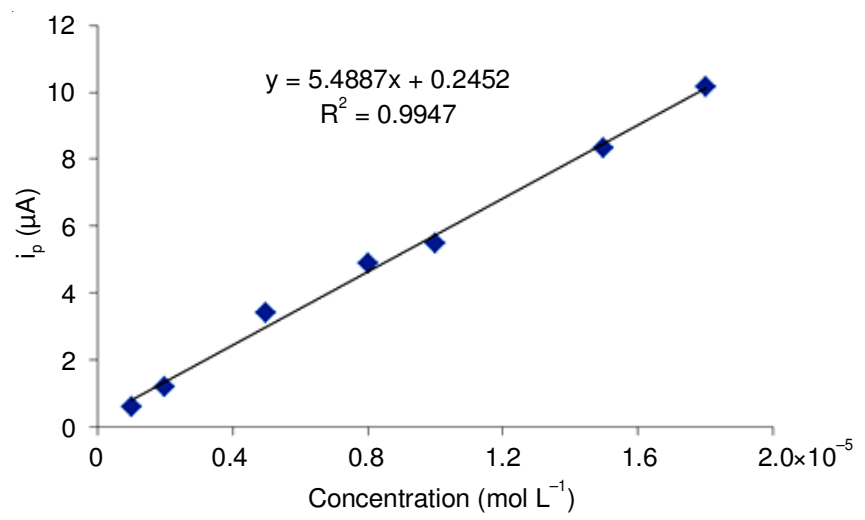

Fig. 12. Calibration graphs of zileuton drug by using SWV method

Validation of analytical procedure: The linearity of calibration curve was obtained for both DPV and SWV techniques and the loss of linearity was probably due to the adsorption of zileuton on the electrode surface. The characteristics of these graphs are given in Table-1. The precision of the method was investigated by repeatedly $(n=5)$ measuring peak potential and peak current of zileuton within a day and over three consecutive days for both techniques. LOD and LOQ were calculated as $(3.3 \mathrm{~s} / \mathrm{m})$ and $(10 \mathrm{~s} / \mathrm{m})$, respectively where $\mathrm{s}$ is standard deviation of response (five runs) and $\mathrm{m}$ is the slope of the calibration curve. LOD and LOQ values confirmed the sensitivity of the proposed methods, These results demonstrated good precision and accuracy $[23,26]$.

Determination of zileuton in pharmaceutical: Both proposed methods (DPV and SWV) were applied to the direct determination of zileuton in tablet using the related calibration curve of the straight lines without sample preparation and after 
TABLE-1

CHARACTERISTICS OF ZILEUTON CALIBRATION PLOTS USING PROPOSED VOLTAMMETRIC METHODS

\begin{tabular}{lcc}
\hline \multicolumn{1}{c}{ Parameters } & $\begin{array}{c}\text { Differential pulse } \\
\text { voltammetry }\end{array}$ & $\begin{array}{c}\text { Square wave } \\
\text { voltammetry }\end{array}$ \\
\hline $\begin{array}{l}\text { Concentration range } \\
(\mathrm{mol} / \mathrm{L})\end{array}$ & $2 \times 10^{-6}-1.2 \times 10^{-5}$ & $1 \times 10^{-6}-1.8 \times 10^{-5}$ \\
Slope $(\mu \mathrm{A} . \mathrm{mol} / \mathrm{L})$ & 0.9281 & 5.4887 \\
Intercept $(\mu \mathrm{A})$ & 0.7121 & 0.2452 \\
Correlation coefficient $(\mathrm{r})$ & 0.9988 & 0.9973 \\
SD & $3.67 \times 10^{-10}$ & $3.84 \times 10^{-10}$ \\
RSD $(\%)$ & 0.0489 & 0.0885 \\
LOD $(\mathrm{mol} / \mathrm{L})$ & $1.3 \times 10^{-9}$ & $2.34 \times 10^{-10}$ \\
LOQ $(\mathrm{mol} / \mathrm{L})$ & $3.95 \times 10^{-9}$ & $6.99 \times 10^{-10}$ \\
\hline
\end{tabular}

an adequate dilution (Table-2). The proposed analysis procedure was successfully applied for the assay of zileuton in its pharmaceutical dosage form. As far as, there is no official method in any pharmacopoeias related to pharmaceutical preparations of zileuton. For this reason, HPLC method [15] was used for comparison and for the reliability of the developed procedures. The results obtained for the formulation are listed in Table-2 and compared with HPLC. The recovery studies were carried out by adding the known amount of pure drug to earlier analyzed pharmaceutical formulations of zileuton. The recovery of the drug was calculated by comparing the concentration obtained from the spiked mixtures with those of pure drug [23]. Table-2 shows a good result, which demonstrates the selectivity of proposed method for the determination of zileuton in commercial tablet forms.

Application on spiked biological samples: The optimized procedure has been successfully applied for the determination of zileuton in protein-free spiked human serum and urine samples. Acetonitrile is tried as a serum and urine precipitating agent. No extraction steps other than the centrifugal protein separation are required prior to the assay of drug. Calibration equation parameters and validation data are shown in Table-3. The obtained recovery results of spiked human serum samples are given in Table-3. The recovery results of zileuton in serum and urine samples are calculated from the related linear regression equations. DPV and SWV curves of zileuton in serum and urine samples are examined and typically compared with that obtained from row material. It could be seen that no oxidation of zileuton drug occurs and no extra peaks are detected in tested biological material in the potential range; whereas the analytical peak appeared.

\section{Conclusion}

In conclusion, the present work demonstrates that highly sensitive electrochemical measurement of zileuton drug is feasible utilizing its extraction on to GCE. The proposed methods showed advantages, such as a short period of the real time of drug analysis and no pretreatment or time consuming in extraction steps were required prior to analysis. Moreover, because of its very limits of detection and quantification, the proposed methods applied in pharmaceutical dosage forms. It also has been successfully applied to the determination of drug in serum and urine.

\section{ACKNOWLEDGEMENTS}

Deanship of Sicentific Research of Najran University has supported this work (Project No.: NU/MID/15/001).

\section{REFERENCES}

1. R.B. Bell, P.R. Young, D. Albert, C. Lanni, J.B. Summers, D.W. Brooks, P. Rubin and G.W. Carter, Int. J. Immunopharmacol., 14, 505 (1992); https://doi.org/10.1016/0192-0561(92)90182-K.

2. S.E. Wenzel and A.K. Kamada, Ann. Pharmacother., 30, 858 (1996).

3. E. Israel, R. Dermarkarian, M. Rosenberg, R. Sperling, G. Taylor, P. Rubin and J.M. Drazen, N. Engl. J. Med., 323, 1740 (1990); https://doi.org/10.1056/NEJM199012203232505.

4. E. Gounaris, M.J. Heiferman, J.R. Heiferman, M. Shrivastav, D. Vitello, N.R. Blatner, L.M. Knab, J.P. Phillips, E.C. Cheon, P.J. Grippo, K. Khazaie, H.G. Munshi and D.J. Bentrem, PLoS One, 6, 1 (2015); https://doi.org/10.1371/journal.pone.0121402.

5. N. Morina, G. Bocari, A. Iljazi, K. Hyseini and G. Halac, Acta Inform. Med., 24, 16 (2016);

https://doi.org/10.5455/aim.2016.24.16-19.

6. W. Berger, M.T. De Chandt and C.B. Cairns, Int. J. Clin. Pract., 61, 663 (2007); https://doi.org/10.1111/j.1742-1241.2007.01320.x.

7. P. Lu, M.L. Schrag, D.E. Slaughter, C.E. Raab, M. Shou and A.D. Rodrigues, Drug Metab. Dispos., 31, 1352 (2003); https://doi.org/10.1124/dmd.31.11.1352.

\begin{tabular}{|c|c|c|c|c|c|c|}
\hline \multicolumn{7}{|c|}{$\begin{array}{c}\text { TABLE-2 } \\
\text { EVALUATION OF THE ACCURACY AND PRECISION OF THE PROPOSED AND OFFICIAL METHODS } \\
\text { FOR THE DETERMINATION OF ZILEUTON IN ITS PHARMACEUTICAL FORMS AT GCE }\end{array}$} \\
\hline Method & Drug & $\begin{array}{c}\text { Taken } \\
(\mu \mathrm{g} / \mathrm{mL})\end{array}$ & $\begin{array}{c}\text { Proposed method } \\
\pm \% \text { RSD }, \mathrm{n}=5\end{array}$ & $\begin{array}{l}\text { Official method } \\
\pm \% \text { RSD, } n=5\end{array}$ & F-test & T-test \\
\hline Differential pulse voltammetry & $600 \mathrm{mg} /$ tablet & 2.5 & $100.02 \pm 0.12$ & $99.91 \pm 1.3$ & 1.13 & 2.04 \\
\hline Square wave voltammetry & $600 \mathrm{mg} /$ tablet & 2.5 & $99.98 \pm 0.94$ & $99.74 \pm 1.00$ & 1.85 & 2.23 \\
\hline
\end{tabular}

TABLE-3

ANALYTICAL RESULTS FOR ZILEUTON DRUG RECOVERIES FROM URINE AND SERUM SAMPLES

\begin{tabular}{|c|c|c|c|c|}
\hline \multirow{2}{*}{ Technique } & \multicolumn{2}{|c|}{ Differential pulse voltammetry } & \multicolumn{2}{|c|}{ Square wave voltammetry } \\
\hline & Serum & Urine & Serum & Urine \\
\hline Concentration range (mol/L) & $2 \times 10^{-6}-1.8 \times 10^{-5}$ & $2 \times 10^{-6}-2.4 \times 10^{-5}$ & $2 \times 10^{-6}-2.0 \times 10^{-5}$ & $2 \times 10^{-6}-3.1 \times 10^{-5}$ \\
\hline Slope $(\mu \mathrm{A} . \mathrm{mol} / \mathrm{L})$ & 0.2240 & 0.074 & 0.145 & 0.097 \\
\hline Intercept $(\mu \mathrm{A})$ & $1.136 \times 10^{-6}$ & $0.446 \times 10^{-6}$ & $0.345 \times 10^{-6}$ & $0.168 \times 10^{-6}$ \\
\hline Correlation coefficient (r) & 0.9920 & 0.9935 & 0.9958 & 0.9967 \\
\hline Recovery (\%) & 99.35 & 100.86 & 99.04 & 99.51 \\
\hline $\operatorname{RSD}(\%)$ & 0.151 & 0.105 & 0.246 & 0.196 \\
\hline
\end{tabular}


8. Y. Qiu, H. Cheskin, J. Briskin and K. Engh, J. Control. Rel., 45, 249 (1997);

https://doi.org/10.1016/S0168-3659(96)01574-X.

9. C.C. Zouboulis, Dermatoendocrinol, 1, 188 (2009); https://doi.org/10.4161/derm.1.3.8368.

10. K.K. Ananda and B.N. Naresh, Int. Res. J. Pharmacy, 3, 154 (2012).

11. K.V. Prasada Rao, M. Tanuja, Y.S. Rao, T.H. Kumar, Int. J. Res. Pharm. Chem., 5, 251 (2015).

12. G.R. Granneman, R.A. Braeckman and K.A. Erdman, Clin. Pharmacokinet., 29(Suppl. 2), 1 (1995);

https://doi.org/10.2165/00003088-199500292-00003.

13. J. Song, Y.B. Zhou, J.S. Ding, Central South Pharmacy, 343 (2005).

14. P. Pian, E. Labovitz, K. Hoffman, C.F. Clavijo, R. Rzasa Lynn, J.L. Galinkin, A.A. Vinks, P. Malik and U. Christians, J. Chromatogr. B Analyt. Technol. Biomed. Life Sci., 937, 79 (2013); https://doi.org/10.1016/j.jchromb.2013.08.014.

15. S.B. Ganorkar and A.A. Shirkhedkar, Arab. J. Chem., 10, 360 (2017); https://doi.org/10.1016/j.arabjc.2013.05.013.

16. V.K. Prasada Rao, M. Tanuja, Y. Srinivasa Rao and H.T. Kumar, Int. J. Drug Dev. Res., 7, 101 (2015).

17. S.B. Ganorkar, A.A. Dhumal and A.A. Shirkhedkar, Arab. J. Chem., 10, 273 (2017); https://doi.org/10.1016/j.arabjc.2014.03.009.
18. N.Y. Sreedhar, M.S. Nayak, K.S. Prasad, P.R. Prasad and C.N. Reddy, E-J. Chem., 7, 166 (2010); https://doi.org/10.1155/2010/251415.

19. P. Katakam, K.A. Shanta and K. Rama Rao, Sci. Pharm., 82, 617 (2014); https://doi.org/10.3797/scipharm.1403-20.

20. H.M. Elqudaby, G.M. Gehad and G.M.G. El Din, Int. J. Electrochem. Sci., 9, 856 (2014).

21. M. Mazloum-Ardakani, H. Rajabi and H. Biotollahi, J. Argent. Chem. Soc., 97, 106 (2009).

22. H.M. Elqudaby, G.G. Mohamed, F.A. Ali and S.M. Eid, Arab. J. Chem., 6, 327 (2013); https://doi.org/10.1016/i.arabic.2011.05.019.

23. B. Uslu, S.A. Özkan and Z. Sentürk, Anal. Chim. Acta, 555, 341 (2006); https://doi.org/10.1016/j.aca.2005.09.034.

24. W. Xu, R. Lei, W. Cao, C. Guo, X. Zhang and S. Wang, J. Anal. Sci. Meth. Instr., 3, 75 (2013); https://doi.org/10.4236/jasmi.2013.32009.

25. M.E. Swartz and I.S. Krull, Analytical Method Development and Validation, Marcel Dekker: New York, edn 1 (1997).

26. J. Ermer and J.H. Miller, Method Validation in Pharmaceutical Analysis; A Guide to Best Practice, Wiley-VCH Verlag GmbH \& Co. KGaA, Weinheim, Germany, pp. 301-336 (2005). 